\title{
Restlessness and life-sustaining activities during four days of sensory deprivation '
}

SEWARD SMITH, THOMAS I. MYERS, NAVAL MEDICAL RESEARCH INSTITUTE, BETHESDA, MARYLAND DONALD B. MURPHY, SYSTEM DEVELOPMENT CORPORATION, SANTA MONICA, CALIFORNIA

Ss undergoing four-day dark, quiet sensory deprivation (SD) showed more restlessness and life-sustaining activity during the day than at night. These results contrast with retrospective reports of disrupted diumal cycles. Daytime restlessness increased over days. Day 2 daytime restlessness predicted later requests for release and, among early release (ER) Ss, correlated inversely with time in isolation. ER Ss were more restless the hour before termination than were all other Ss during that hour.

In early studies of sensory deprivation (SD), Heron (1961) noted that Ss appeared to be progressively more restless over time in isolation. Since then several other investigators have attended to indices of restless activity exhibited by Ss undergoing such experiences (Holt \& Goldberger, 1960; Leiderman, 1962; Mendelson, Kubzansky, Leiderman, Wexler, DuToit, \& Solomon, 1960; Suedfeld \& Vernon, 1965; Zuckerman, Persky, Hopkins, Murtaugh, Basu, \& Schilling, 1966). Most of these studies required relatively short exposures to isolation. Also, crude restlessness indices (e.g., observations) were involved. Trends toward increased restlessness were noted and it was inferred that the more restless individual was less suited to isolation.

The data to be reported in this paper, constituting part of the HumRRO SD program, were planned to provide more objective and continuous information about restless activity and general life-sustaining behavior of isolated Ss. Major additional purposes were: the examination of a longer time period $(96 \mathrm{~h})$, and comparison of the behavior of successful and unsuccessful (i.e., early release) $\mathrm{Ss}^{2}$

Method

Activity patterns of 48 volunteer U. S. Army enlisted men were examined while they attempted to remain in dark, quiet SD for 96 consecutive hours. There were 23 long staying (LS) Ss who stayed the full time. Twenty-five Ss requested early release (ER). No comparable data could be obtained from the control group Ss, who lived in a barracks building. Each of the eight light proof and sound proof cubicles used in the experiment was equipped with a bed, a chemical toilet, and a refrigerator containing bottled water and canned liquid food. Switches monitored the removal of any water bottle or can of food, and also indicated the lifting of the lid of the chemical tollet. An arrangement of switches, mounted beneath the bed, Indicated when $S$ was on or off his bed. A rate of change of movement detector, placed beneath the center of the bed, provided continuous information that was transformed into a number of relay closures proportional to the amount of gross restlessness occurring on the bed. 3 Data totals were printed every $10 \mathrm{~min}$ throughout the four-day isolation period. More procedural details and additional data from the HumRRO SD research program are presented in two other reports (Myers, Murphy, Smith, \& Goffard, 1966; Smith, Myers, \& Murphy, 1967). Resulis and Discussion

Restlessness activity was sampled from a daytime and a nighttime 6-h period (both from 11:00 to 5:00) on each of the four successive experimental days. S's restlessness rate was computed for each time block by dividing the total number of restlessness counts by the total number of minutes spent on the bed. The rate is thus an average number of counts per minute. Figure 1 shows restlessness rate changes from night to day and from Day 1 to Day 4 for 23 LS Ss.

Analysis of variance of these data indicates that $\mathrm{Ss}$ were more restless during the daytime than at night $(p<.005)$. Restlessness also increased over days ( $p<$ $.001)$. As reflected in the significant interaction ( $p$ $<.001)$, however, the majority of this change was due to increasing daytime restlessness that more than doubled from the first day to the last.

A comparison was made between LS Ss and ER Ss. These groups did not differ during the Day 1 time perlod, perhaps because Ss typically slept a great deal during these first hours of isolation. Day 2 data, however, revealed higher daytime restlessness $(p<.001)$ for ER as compared to LS Ss. Fifteen of $18 \mathrm{ER} \mathrm{Ss,} \mathrm{but} \mathrm{only} \mathrm{five}$ of 23 LS Ss, exhibited scores above the median.

Further evidence of the relationship between restlessness and isolation endurance was afforded by the correlation between these factors within the group of

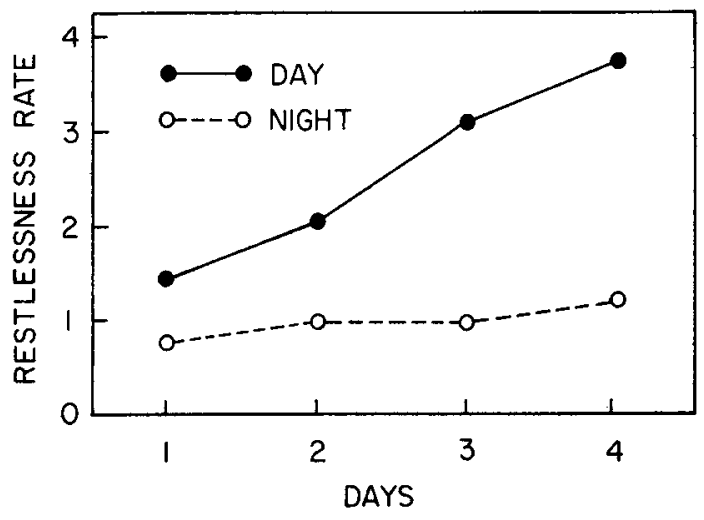

Fig. 1. Restlessness rate as a function of time of day and day of experiment. 


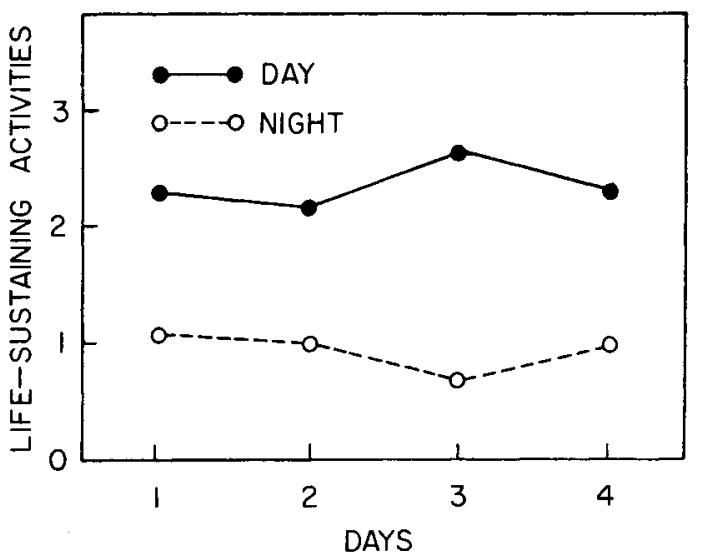

Fig. 2. Life-sustaining activities as a function of time of day and day of experiment.

ER Ss. A rank order correlation of -.62 ( $p<.02)$ was obtained between Day 2 restlessness and amount of time spent in isolation before requesting release, indicating that the more restless Ss tended to depart sooner. Also, in 17 of 24 cases the ER Ss' restlessness rates in the hour just prior to request for release were above the average of all other Ss still in isolation at that time $(p<.05)$.

The life-sustaining activities included the taking of food and water and the use of the chemical toilet. The overall patterns of these life-sustaining activities were highly similar and the occurrence of each event was relatively infrequent. Hence, for analysis, a composite of food, water, and tollet activity was used as the measure of life-sustaining activities, during similar 6-h night and day time blocks. To compute S's life-sustaining activities score for any 6-h period, he was given a point if he had taken food, or water, or had used the tollet at any time during the period. Thus, his score for a given 6-h period was from 0 to 3 , depending upon how many of the three activitles had occurred at least once. Figure 2 shows the life-sustaining activities data for the LS Ss.

Analysis of variance of these activity scores reveals a significant $(p<.001)$ night vs day difference. Although the interaction term reaches statistical significance $(p<.05)$, no interpretable pattern emerges. No significant differences were found between these LS Ss and ER Ss on the life-sustaining activities measure.

Two general conclusions appear to be borne out by these restlessness and life-sustaining-activities data. First, these measures present clear-cut evidence that diurnal cycles are likely to be maintained in isolation, at least during a four-day period. The data supporting this conclusion appear to be dependent upon few if any cues of external origin, such as lights and sounds or temperature changes. Interestingly, this uniformity of diurnal pattern contrasts with Ss' retrospective reports, which suggest that, during isolation, they experienced disruptions in the normal cycles of such activities as eating and sleeping. Second, the restlessness data presented here, combined with a considerable amount of retrospective report information, indicate that restlessness is an important ingredient of the isolation experience, with greater restlessness leading to earlier departure from confinement. There is the strong suggestion from this finding that amount of restlessness during short term isolation, or during a brief exposure to a waiting room situation, might serve as a useful predictive index of a person's ability to withstand boring, monotonous environments characterized by a prolonged dearth of sensory and social stimulation.

\section{References}

Heron, W. Cognitive and physiological effects of perceptual isolation. In P. Solomon et al (Eds.), Sensory deprivation. Cambridge, Mass.: Harvard University Press, 1961. Pp. 6-33.

Holt, R. R., \& Goldberger, L. Assessment of individual resistence to sensory alteration. In B. E. Flaherty (Ed.), Psychophysiological aspects of space flight. New York: Columbia University Press, 1961. Pp. 248-262.

Leiderman, P. H. Imagery and sensory deprivation: an experimental study. Aerospace Med. Div. Rep. No. MRL-TDR-62-28, May, 1962.

Mendelson, J., Kubzansky, P., Leiderman, P. H., Wexler, D., DuToit, D., \& Solomon, P. Catechol amine excretion and behavior during sensory deprivation. Arch. gen. Psychiat., 1960, 2, 147-155.

Myers, T. I., Murphy, D. B., Smith, S., \& Goffard, S. J. Experimertal studies of sensory deprivation and social isolation. Alexandria, Va.: Human Resources Research Office, June, 1966 (Tech. Rep. 66-8).

Smith, S., Myers, T. 1., \& Murphy, D. B. Activity pattern and restlessness during sustained sensory deprivation. Amer. Psychologist, 1962, 17, 389 (Abstr.).

Smith, S., Myers, T. I., \& Murphy, D. B. Vigilance during sensory deprivation. Percept. mot. Skills, 1967, 24, 971-976.

Suedfeld, P., \& Vemon, J. Stress and verbal originality in sensory deprivation. Psychol. Rec., 1965, 15, 567-570.

Zuckerman, M., Persky, H., Hopkins, T. R., Murtaugh, T., Basu, G. K., \& Schilling, Mary. Comparisons of stress effects of perceptual and social isolation. Arch. gen. Psychiat., 1966, 14. 356-365.

\section{Notes}

1. The data reported here were collected while the writers were staff members of HumRRO Division No. 3 (Recruit Training), Presidio of Monterey, California, under Dept. of Army contract with George Washington University. The opinions and statements contained herein are the private ones of the writers and are not to be construed as official or as reflecting the views of the Navy Dept., the Naval Service at large, or as reflecting the official position of the Dept. of the Army.

2. These data have been previously reported in an APA paper (Smith, Myers, \& Murphy, 1962).

3. Benjamin Viljoen and $\mathrm{P}$ aul $\mathrm{M}$. Haas made sizeable instrumentation contributions. 